\title{
Future pattern of Asian drought under global warming scenario
}

Kim D.W., Byun H.R., Lee S.M.

in

López-Francos A. (ed.).

Drought management: scientific and technological innovations

Zaragoza : CIHEAM

Options Méditerranéennes : Série A. Séminaires Méditerranéens; n. 80

2008

pages 113-116

Article avai lable on line / Article disponible en ligne à l'adresse :

http://om.ciheam.org/article.php?IDPDF=800429

To cite th is article / Pou r citer cet article

Kim D.W., Byun H.R., Lee S.M. Future pattern of Asian drought under global warming scenario. In : López-Francos A. (ed.). Drought management: scientific and technological innovations. Zaragoza : CIHEAM, 2008. p. 113-116 (Options Méditerranéennes : Série A. Séminaires Méditerranéens; n. 80)

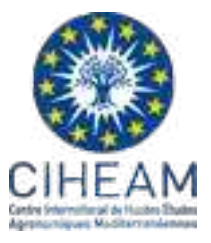

http://www.ciheam.org/

http://om .ciheam.orgl 


\title{
Future pattern of Asian drought under global warming scenario
}

\author{
D.W. Kim, H.R. Byun and S.M. Lee \\ Dept. of Environmental Atmospheric Sciences, Pukyong National University, Busan, Korea
}

\begin{abstract}
SUMMARY - As impacts of global warming, aspects of drought over Asia at the end of the 21 st century are estimated by Multi-Model Ensemble method from daily precipitation data of fifteen coupled climate model simulations under the SRES A1B scenario assessing the consistency of results among different models. Over most areas, increases in mean precipitation are projected. The increase rate of precipitation is the highest in North Asia and significant in all seasons. The increase over Southern and Eastern Asia (Asian monsoon regions) is caused by the substantial rise in monsoon rainfall. It is also accompanied by the enhanced daily variability of precipitation and the occasional dry winters. However the significant decrease in mean precipitation is predicted over West Asia, mainly for first half of the year. These changes on precipitation climatology are translated to those of drought climatology by using the Effective Drought Index. Over most of the areas for all seasons it is projected that the frequency of drought will be reduced, the duration shortened. Over the Asian monsoon regions, however, the frequency and intensity of extremes will significantly increase, more remarkably during the spring. The increases of the frequency and the intensity are significant over West Asia, especially in extreme summer drought.
\end{abstract}

Key words: Global warming, drought frequency, drought intensity, drought duration, effective drought index.

\section{Introduction}

Intergovernmental Panel on Climate Change report (IPCC, 2001) indicated that Asian water resources are threatening by enhanced variability in precipitation climate under global warming. However, there have been few studies that tried to estimate quantitatively the hydrological disasters we should expect. This study has an interest on the disaster caused by the deficiency of water resources especially in drought conditions.

Several modeling studies with increased green house gases have shown that Asian monsoon rainfall is likely to increase. It accompanied with not only an enhancement of monsoon inter-annual variability (e.g. Meehl and Washington, 1993; Hu et al., 2000) but also an increase in the subseasonal variability (Lal et al., 2000). As a result, extreme excesses and deficits of Asian monsoon rainfalls are expected to be intensified (Kripalani et al., 2007). It is also expected that the relatively weak rainfall days will be decreased while the frequencies of non-precipitating and heavy rainfall days will be significantly increased (Kimoto et al., 2005). It still remains a challenge to quantify how Asian drought will be responded to those changes of precipitation climate.

\section{Data and method}

Fifteen Global Circulation models (GCMs) used this study are a part of the IPCC's data archives at Lawrence Livermore National Laboratory. All models start their integration from the "20th Century Climate in Coupled Model" run, in which the level of anthropogenic forcing is based on historical data of the late 19th century through the 20th century. From the end of the 20C3M run, SRES-A1B conditions is imposed and integrated through year 2100. The SRES-A1B assumes rapid economic and population growth that peaks in mid-century and declines thereafter. Two time periods of twenty years each were chosen for analysis: the late 20th century (1981-2000; hereafter 20C3M) and the late 21st century (2081-2100; hereafter A1B). Multi-Model Ensemble (MME) of $15 \mathrm{GCMs}$ [following model data are used in this study: CCSM3, CGCM3.1(T47), CGCM3.1(T63), CNRM-CM3, CSIRO-Mk3.0, ECHAM5/MPI-OM, FGOALS-g1.0, GFDL-CM2.0, GFDL-CM2.1, GISS-AOM, GISS-ER, INM-CM3.0, MIROC3.2(hires), MIROC3.2(medres), MRI-CGCM2.3.2] is analyzed.

The Effective Drought Index (EDI; Byun and Wilhite, 1999) was applied to measure a drought. It is a kind of standardized value that means $66.7 \%$ of whole variance is in the range of \pm 1.0 . 


\section{Results}

\section{Change in precipitation climate}

Figure 1 (a) shows the difference in MME mean precipitation between A1B and 20C3M. Precipitation is expected to increase over North (5 25\%), East (5 15\%), and South (5 10\%) Asia. However decreases from 0 to $25 \%$ are predicted over West Asia.

The difference in MME Coefficient of Variation (CV) between A1B and 20C3M is illustrated in Fig. 1 (b). A considerable increase in the CV is shown across West Asia and the Asian monsoon regions (South and East Asia; hereafter AMR). The increase over West Asia is an inevitable result of the large decrease in mean precipitation. However the increase over the AMS, where the mean precipitation increased, is interpreted as an enhancement of precipitation variability.

(a) Mean Precipitation

(b) Coefficient of Variation

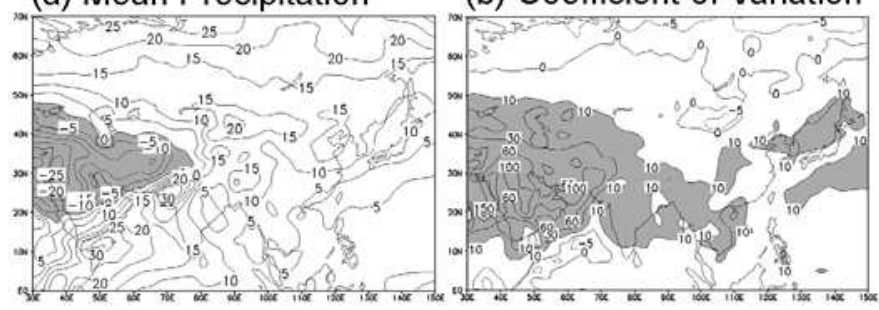

Fig. 1. Differences in multi-model ensemble (a) mean precipitation and (b) coefficient of variation of precipitation between the SRES-A1B experiments and the 20C3M experiments.

The projected (A1B) and simulated (20C3M) seasonal cycles for the MME area-averaged precipitation are shown in Fig. 2. The difference between the two experiments is presented by a bar graph. The error bar depicts the range of uncertainty from model differences. The cross mark indicates the consistency index, the sign of the index reflects the direction of change predicted by the majority models and the magnitude of index indicates the percentage of the majority models out of all models. In North Asia (Fig. 2a), models are highly consistent in predicting the increases throughout the year. Seasonal cycle change over West Asia (Fig. 2b) is characterized by the successive reduction from Jan to Jul. In the AMR (Figs. 2c and d), significant increases are predicted during summer months. During colder season, however, the decreases are dominant in South Asia and the increases in East Asia are not clear compared to the ranges of model uncertainty.

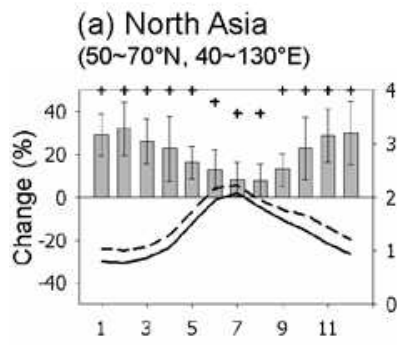

(b) West Asia $\left(15 \sim 45^{\circ} \mathrm{N}, 30 \sim 70^{\circ} \mathrm{E}\right)$

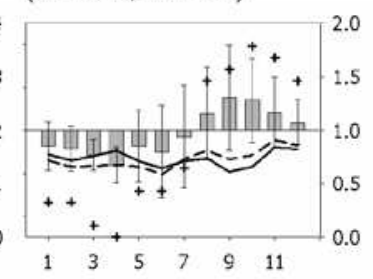

(c) South Asia $\left(10 \sim 25^{\circ} \mathrm{N}, 70 \sim 120^{\circ} \mathrm{E}\right)$

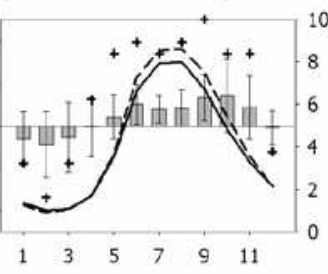

(d) East Asia

$\left(25 \sim 45^{\circ} \mathrm{N}, 110 \sim 145^{\circ} \mathrm{E}\right)$

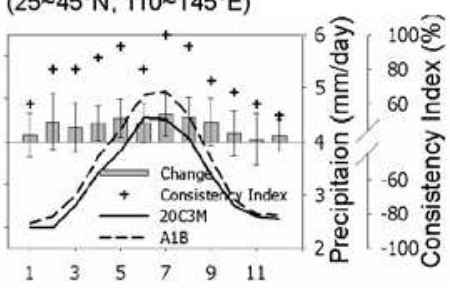

Fig. 2. Multi-model ensemble precipitation seasonal cycle for the $20 \mathrm{C} 3 \mathrm{M}$ experiments (solid line) and the A1B experiments (dash line) and its percentage changes (bars). Inter-model variability and consistency index is depicted by error bar and cross mark, respectively.

\section{Future drought climate}

A drought event is defined as the value of the minimum EDI smaller than -1.0 (general drought) and -2.0 (extreme drought). The onset is then defined as the date when EDI drops below -0.5, and the 
secession as the date when EDI exceeds this value last. The duration is a period between onset and secession dates, and the intensity is a minimum EDI during the duration.

In Fig. 3 we plot the differences in three MME mean drought variables (frequency, intensity, and duration) between $\mathrm{A} 1 \mathrm{~B}$ and $20 \mathrm{C} 3 \mathrm{M}$. The upper and bottom panels are general and extreme drought, respectively. For general drought, it can be seen that the mean frequency and the mean duration are predicted to decrease over most of Asia while they expected to increase over West Asia. However, the mean intensity strengthens not only over West Asia but also over the AMR where mean precipitation increased. This contradicted aggravation of drought over the AMR is more clearly shown in the frequency and the intensity of extreme drought.

(a) Frequency

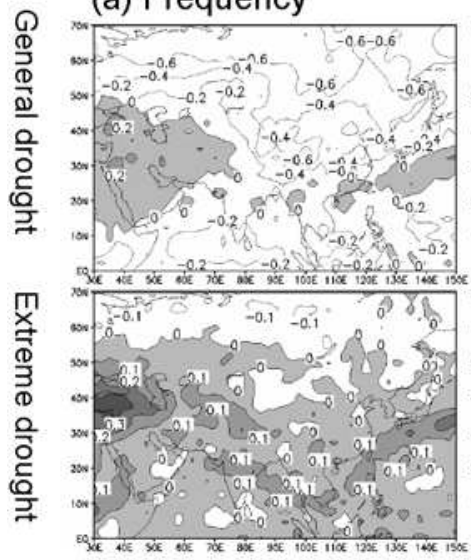

(b) Intensity

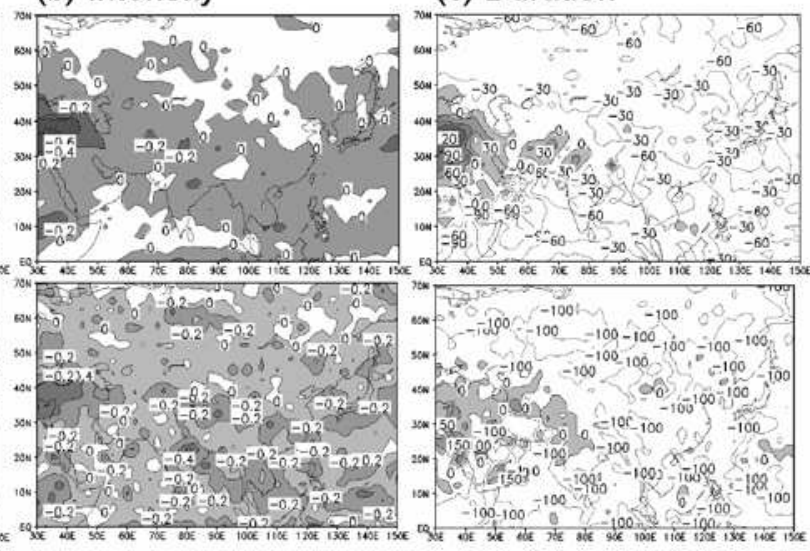

Fig. 3. Difference (A1B - 20C3M) in multi-model ensemble (a) mean frequency (per a year), (b) mean intensity (minimum EDI), and (c) mean duration (days) for general (upper panels) and extreme (bottom panels) drought events.

Figure 4 shows MME difference of area-averaged monthly total severe $(-2<E D \mid<-1$; left panels) and extreme $(E D I<-2$; right panels) drought days. Inter-model variability and consistency index is depicted by a error bar and a cross mark, respectively. For both kinds of drought days, the year-round decrease and increase is clearly predicted in North and West Asia, respectively. In the AMR, it is notable that extreme drought days expected to increase throughout the year though severe ones predicted to decrease as well as in North Asia. This strengthening of extreme drought in the AMR is more evident during spring.

\section{Conclusions}

Impacts of global warming on the Asian precipitation and drought climate at the end of $21 \mathrm{st}$ century are investigated using fifteen GCMs under the SRES-A1B scenario. Projections of the mean precipitation show wetness over most of Asia and dryness over West Asia. In particular over North Asia, there are no possibilities to worsen drought conditions because models consistently predicted the large increase in mean precipitation for all seasons with the decreased variability. The significant increases in the mean precipitation are predicted over South and East Asia (Asian monsoon regions) too. They are mainly attributed to the substantial rise in monsoon rainfall. It is also accompanied by the enhanced daily variability of precipitation and the occasional dry winters. Drought is most likely to be severe over West Asia by a significant decrease in mean precipitation and the successive decreases in seasonal rainfall for first half of year.

We estimated the actual responses in the frequency, the intensity, and the duration of drought using the Effective Drought Index. The frequency and the intensity of drought over West Asia tends to be increased, while over extra-West Asia the frequency and the duration are expected to decrease, more clearly over North Asia. However, in case of extreme drought, the frequency and the intensity tend to increase significantly over the Asian monsoon regions. 


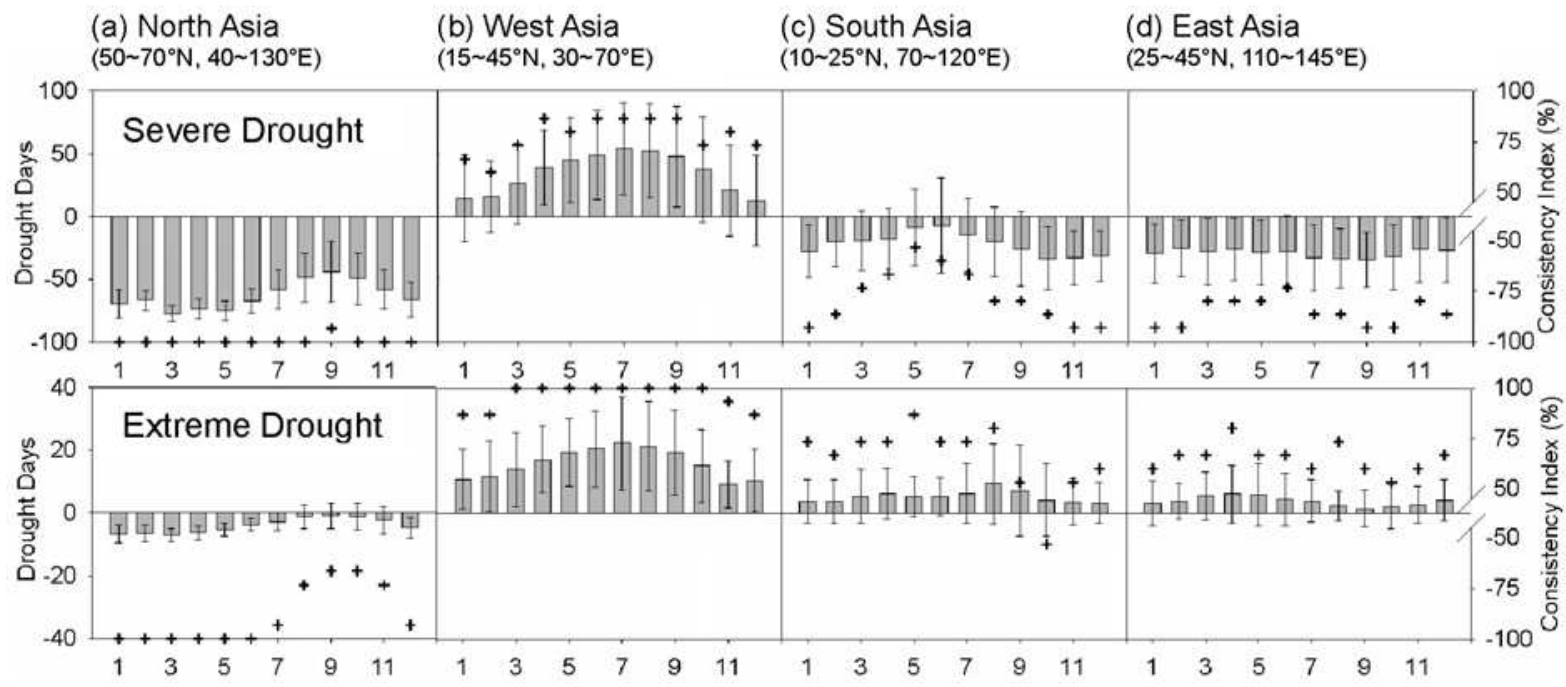

Fig. 4. Difference (A1B - 20C3M) in multi-model ensemble monthly total severe (-2<EDI<-1; left panels) and extreme $(\mathrm{EDI}<-2$; right panels) drought days which are area-averaged. Inter-model variability (intra-ensemble standard deviation) and consistency index, respectively.

The seasonal drought change has also analyzed. Over all regions, the weakening or strengthening of drought is shown throughout the year without seasonal inconsistency. The weakening of North Asian drought is more evident during winter and the strengthening of West Asian drought does during summer. Over the Asian monsoon regions, although, the year-round weakening of drought appeared as well as North Asia, the year-round strengthening of extreme drought is also predicted, especially during pre-monsoon season.

\section{References}

Byun, H.R. and Wilhite, D.A. (1999). Objective quantification of drought severity and duration. J. Climate, 12: 2747-2756.

Hu, Z.Z., Latif, M., Roeckner, E. and Bengtsson, L. (2000). Intensified Asian summer monsoon and its variability in a coupled model forced by increasing greenhouse gas concentrations. Geophys. Res. Lett., 27: 2681-2684.

IPCC (2001). Climate Change 2001: Impacts, Adaptation and Vulnerability. McCarthy, J.J., Canziani, O.F., Leary, N.A., Dokken, D.J. and White, K.S. (eds). Cambridge University Press, pp. 535-581.

Kimoto, M., Yasutomi, N., Yokoyama, C. and Emori, S. (2005). Projected changes in precipitation characteristics around Japan under the global warming. SOLA, 1: 85-88.

Kripalani, R.H., Oh, J.H., Kulkrni, A., Sabade, S.S. and Chaudhari, H.S. (2007). South Asian summer monsoon precipitation variability: Coupled climate model simulations and projections under IPCC AR4. Theor. Appl. Climatol., 90: 133-159.

Meehl, G.A. and Washington, W.M. (1993). South Asian summer monsoon variability in a model with doubled atmospheric carbon dioxide concentration. Science, 260: 1101-1104.

Lal, M., Meehl, G.A. and Arblaster, J.M. (2000). Simulation of Indian summer monsoon rainfall and its intraseasonal variability. Reg. Environ. Change, 1: 163-179. 